\title{
Avaliação físico-química do bicarbonato de sódio dispensado em farmácias
}

Physicochemical analysis of sodium bicarbonate dispensed in pharmacies

\author{
A. A. V. Nascimento ${ }^{1, *}$; F. das C. R. Magalhães ${ }^{1}$; A. M. dos Santos²; E. R. C. \\ Borba $^{1}$ \\ ${ }^{1}$ Departamento de Farmácia, Universidade Federal do Maranhão, 65080-805, São Luís - MA, Brasil \\ ${ }^{2}$ Departamento de Saúde Pública, Programa de Pós-Graduação em Saúde Coletiva, Universidade Federal do \\ Maranhão, 65080-805, São Luís - MA, Brasil \\ *andreduvalle17@gmail.com \\ (Recebido em 11 de janeiro de 2019; aceito em 25 de agosto de 2019)
}

\begin{abstract}
O controle de qualidade é um conjunto de atividades realizadas para assegurar que o produto não seja entregue ao consumidor, sem antes cumprir as especificações definidas. Este estudo avaliou a qualidade físico-química do bicarbonato de sódio, na forma farmacêutica de pó, dispensado em farmácias no município de São Luís- MA. As análises foram realizadas de acordo com os métodos descritos na Farmacopeia Brasileira $5^{\text {a }}$ edição. Foram utilizadas 10 amostras do mesmo lote de cada fabricante, sendo analisados 3 fabricantes diferentes, realizando-se ensaios de identificação, pureza, determinação de peso e doseamento. As amostras cumpriram as especificações farmacopeicas nos ensaios de identificação e pureza. Nos testes para determinação de peso, as amostras analisadas dos três fabricantes cumprem o teste com um valor encontrado na média dos resultados de $100 \%$ da massa em relação ao peso declarado, indicando homogeneidade no envase e o fornecimento do produto na quantidade informada. No ensaio de doseamento, os três fabricantes: A $(99,73 \%)$, B $(100,16 \%)$ e C $(99,94 \%)$ apresentaram-se em conformidade com a especificação da Farmacopeia Brasileira $5^{\text {a }}$ edição. Os resultados encontrados demonstram pouca variação entre as unidades e a média, observado em análise estatística, sugerindo homogeneidade entre as amostras analisadas no estudo. Constatou-se que as amostras analisadas dos três fabricantes cumpriram os testes de qualidade físico-químicos aplicados no estudo, sugerindo estar em conformidade com os padrões de qualidade preconizados.
\end{abstract}

Palavras-chave: Bicarbonato de Sódio; análise físico-química; qualidade.

Quality control is a set of activities performed to ensure that the product is not delivered to the consumer without first meeting the defined specifications. This study evaluated the physicochemical quality of sodium bicarbonate, in powdered pharmaceutical form, dispensed in pharmacies in the city of São LuísMA. Analyzes were performed according to the methods described in the Brazilian Pharmacopoeia 5th edition. Ten samples from the same batch were used from each manufacturer, and three different manufacturers were analyzed, performing identification, purity, weight and assay assays. The samples met pharmacopeic specifications in the identification and purity assays. In the tests for weight determination, the samples analyzed from the three manufacturers fulfill the test with a value found on the average of the results of $100 \%$ of the mass in relation to the declared weight, indicating homogeneity in the filling and the supply of the product in the informed quantity. In the assay, the three manufacturers: A (99.73\%), B $(100.16 \%)$ and C (99.94\%) were in accordance with the specification of the Brazilian Pharmacopoeia 5th edition. The results show little variation between the units and the average, observed in statistical analysis, suggesting homogeneity between the samples analyzed in the study. It was found that the samples analyzed from the three manufacturers complied with the physicochemical quality tests applied in the study, suggesting to comply with the recommended quality standards.

Keywords: Sodium Bicarbonate; physicochemical analysis; quality.

\section{INTRODUÇÃO}

O controle de qualidade é um conjunto de atividades realizadas com a finalidade de assegurar que os ensaios necessários e relevantes sejam executados e que o produto não seja disponibilizado para uso e venda até que cumpra com as especificações pré-estabelecidas [1]. Na indústria farmacêutica, o controle de qualidade é de fundamental importância para atestar a qualidade final do produto, e consequentemente, do medicamento dispensado ao paciente [2]. Por esta razão, é 
imprescindível que toda empresa possua laboratório de controle de qualidade autônomo, podendo terceirizar análises quando a legislação permitir [1].

As análises de controle de qualidade permitem comprovar se o medicamento mantém íntegras as suas propriedades físicas, químicas, microbiológicas, terapêuticas e toxicológicas, garantindo assim a sua estabilidade. Ele deve manter estes parâmetros dentro das especificações definidas durante todo o seu prazo de validade, pois neste período, a segurança, a qualidade e a eficácia do medicamento, mantido nas condições ideais de embalagem e de armazenamento, são asseguradas pelo fabricante $[3,4]$.

De acordo com a RDC/ANVISA $n^{\circ} 98 / 2016$, os medicamentos podem ser classificados segundo o enquadramento na categoria de vendas em: medicamentos de venda sob prescrição e os isentos de prescrição. Legalmente, os medicamentos sob prescrição têm sua dispensação restrita à apresentação da prescrição. Neste grupo há os medicamentos em que não se exige retenção de receita na Farmácia, apresentando uma tarja vermelha na embalagem e os dizeres "VENDA SOB PRESCRIÇÃO MÉDICA"; e os com retenção de receita, com uma tarja vermelha ou preta na embalagem e os dizeres "VENDA SOB PRESCRIÇÃO MÉDICA: SÓ PODE SER VENDIDO COM RETENÇÃO DA RECEITA” [7].

Já os medicamentos isentos de prescrição ou MIPs são os que estão disponíveis ao autosserviço em farmácias e não necessitam de prescrição médica para que sejam dispensados. Exige-se que passem por uma avalição da ANVISA no ato do registro [7], devendo cumprir algumas exigências descritas pela RDC/ANVISA n 98, de 2016, tais como: já ter um tempo mínimo de comercialização do princípio ativo, segurança, indicação para sinais e sintomas de doenças não graves e com evolução inexistente ou muito lenta e de fácil identificação, utilização por um curto período de tempo ou tempo previsto em embalagem e não apresentar potencial de dependência [8]. Como exemplo de MIPs, pode-se citar o bicarbonato de sódio classificado como antiácido, e assim como todo medicamento pode ter sua qualidade comprometida [5, 6, 7].

O bicarbonato de sódio, também conhecido como Sal de Vick, por ser considerado um medicamento de baixo risco do tipo antiácido, está classificado na Lista de Medicamentos de baixo risco sujeitos a notificação simplificada, na forma farmacêutica de pó, conforme a RDC/ANVISA $n^{\circ} 107$, de 5 de setembro de 2016 [6, 12]. Tendo esta como uma de suas principais funções, o bicarbonato de sódio pode neutralizar rapidamente o ácido gástrico, formando água, dióxido de carbono e sódio, o que resulta na elevação do pH estomacal $(>5)$ e inibição da atividade péptica. $\mathrm{O}$ efeito costuma ser rápido, mas pode desencadear uma alcalose em doses elevadas; ou seja, o aumento do pH sanguíneo. Além disso, exige-se cautela em pacientes com hipertensão ou sobrecarga hídrica, pois o seu uso pode resultar em retenção significativa de sódio [13, 14]. Ele também tem importância terapêutica na acidose metabólica, diarreia, intoxicações por ácidos exógenos ou externos ao organismo, uremia e acidose lática, podendo ainda ser usado na produção de cremes dentais, desodorantes e xampus [10,11]. Esta substância está presente nas formas farmacêuticas de solução injetável e de pó.

O bicarbonato de sódio também pode ser utilizado em extintores de incêndio, conhecidos como pó químico, na indústria têxtil de polímeros e na culinária, como componente do fermento químico [11]. Costuma ser estável quando embalado hermeticamente e em condições normais de tem[peratura e pressão. No entanto, quando exposto ao ar livre e calor acima de $50^{\circ} \mathrm{C}$, libera gás carbônico [15].

$\mathrm{O}$ bicarbonato de sódio $\left(\mathrm{NaHCO}_{3}\right)$ ou hidrogenocarbonato de sódio é um sal formado pelo cátion de sódio $\left(\mathrm{Na}^{1+}\right)$ e pelo ânion poliatômico hidrogenocarbonato $\left(\mathrm{HCO}^{3}\right)^{2-}$, sendo descrito primeiramente no Monte Vesúvio, Itália, em 1928. Na natureza, é encontrado com maior predominância no mineral nahcolita, apresentando uma estrutura cristalina monoclínica. É um constituinte normal do organismo, sendo responsável pelo equilíbrio ácido-base. Apresenta-se como um sólido cristalino, na forma de pó branco, inodoro, com sabor ligeiramente salgado e alcalino, podendo ser produzido sinteticamente $[6,9,10,11]$. Pode também ser obtido através do processo de Solvay. No processo, utiliza-se amônia, dióxido de carbono, água e solução de salmouro (cloreto de sódio concentrado) para a obtenção de bicarbonato de sódio e de carbonato de sódio.

Dessa forma, além das farmácias, o bicarbonato de sódio pode ser encontrado em estabelecimentos de venda livre, como supermercados. Destaca-se, no entanto, que para estes 
ambientes, a venda do bicarbonato de sódio não é para fins medicamentosos e seguem outras legislações.

Considerando-se a fácil aquisição desse medicamento e a necessidade de manutenção dos parâmetros de qualidade preconizados pelas legislações sanitárias vigentes, o estudo buscou verificar se as amostras selecionadas e analisadas cumprem os requisitos de qualidade físico-

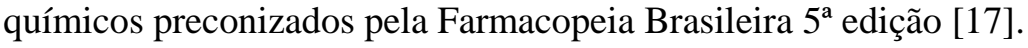

\section{MATERIAL E MÉTODOS}

O estudo foi realizado no laboratório de controle de qualidade físico-químico de medicamentos da Universidade Federal do Maranhão (UFMA), nos meses de agosto a novembro, conforme as especificações da Farmacopeia Brasileira $5^{\text {a }}$ edição [17].

Analisou-se amostras de bicarbonato de sódio, na forma farmacêutica sólida, acondicionado em recipientes para doses múltiplas (pós). Foram analisadas 10 amostras do mesmo lote, sendo avaliados 3 fabricantes diferentes, de $50 \mathrm{mg}$ a $100 \mathrm{mg}$, comercializados em farmácias, no município de São Luís- MA.

Duas farmácias foram selecionadas aleatoriamente para a aquisição das amostras, em decorrência da baixa variabilidade de laboratórios comercializados na região. Levou-se em conta a dificuldade em se encontrar laboratórios distintos entre elas. As amostras de diferentes marcas que foram apresentadas em primeira instância nos estabelecimentos, como as que possuem maior saída, foram as selecionadas para a realização das análises. Totalizando um estudo estimado com 30 amostras que foram adquiridas no mês de agosto e analisadas nos meses de outubro a novembro do ano de 2018.

\subsection{Ensaios de identificação}

Preparou-se uma solução de bicarbonato de sódio 5\% (p/v) em água isenta de dióxido de carbono, e adicionou-se $0,1 \mathrm{~mL}$ de solução de fenolftaleína SI a $5 \mathrm{~mL}$ desta solução. Observouse o desenvolvimento de coloração rósea ou não. Ao ser aquecida em uma chapa aquecedora, observou-se a ocorrência de liberação de gás e a mudança de coloração da solução para vermelho, quando presente o bicarbonato de sódio [16].

Para o preparo da água isenta de dióxido de carbono, usou-se água destilada fervida durante, no mínimo, cinco minutos e protegida do ar atmosférico durante o resfriamento e armazenagem. Sendo após o resfriamento usada nos testes requeridos [16].

\subsection{Ensaios de pureza}

Realizaram-se dois testes descritos na Farmacopeia Brasileira $5^{a}$ edição [16], abaixo citados: Aspecto da solução, sendo analisado se a solução 5\% (p/v) em água isenta de dióxido de carbono permaneceria límpida, e Ensaio para carbonatos, onde o $\mathrm{pH}$ desta solução recém preparada, não pode ser superior a 8,6. Para a análise do pH, utilizou-se o pHmetro T-1000 ® de 0,02 pH de precisão.

\subsection{Teste de determinação de peso}

Pesaram-se 10 unidades do bicarbonato de sódio individualmente, em uma balança analítica, modelo Acculab, marca Sartorius Group ${ }^{\circledR}(\mathrm{d}=0,0001)$. O conteúdo foi removido e os recipientes foram lavados, utilizando um solvente adequado. Em seguida, secaram-se os recipientes em uma estufa de esterilização e secagem Orion 515 Fanem ${ }^{\circledR}$ até peso constante. A diferença entre as duas pesagens representa o peso do conteúdo [16].

De acordo com a Farmacopeia Brasileira $5^{\mathrm{a}}$ edição, os critérios de avaliação da determinação de peso especificam que as apresentações com até $60 \mathrm{~g}$ de peso declarado devem ter um percentual mínimo de $90 \%$ do peso declarado; enquanto que, nas apresentações entre $60-150 \mathrm{~g}$ de peso declarado deve-se apresentar um percentual mínimo em relação ao peso declarado de 92,5\% [16]. 


\subsection{Doseamento}

Dissolveu-se 1,5 g do bicarbonato de sódio em $50 \mathrm{~mL}$ de água isenta de dióxido de carbono, e se titulou a solução com ácido clorídrico M SV, utilizando $0,2 \mathrm{~mL}$ de alaranjado de metila SI como indicador. As amostras devem conter no mínimo, 99,0\% e, no máximo, 101,0\% de $\mathrm{NaHCO}_{3}$ (cada mL de ácido clorídrico M SV corresponde a 84,010 mg de $\mathrm{NaHCO}_{3}$ ) [16].

\subsection{Análise estatística}

Realizou-se a análise descritiva das variáveis em estudo. As variáveis numéricas (doseamento, peso e o $\mathrm{pH}$ ) serão apresentadas por meio de médias $\left(\mu_{\mathrm{x}}\right)$ e desvio padrão $\left(\sigma_{\mathrm{x}}\right)$. Para avaliar a homogeneidade das amostras em estudo, calculou-se o desvio padrão relativo. A análise do comportamento da variável "peso" foi realizada por meio de gráficos de controle, os quais facilitam a visualização da variação existente entre as amostras de um mesmo laboratório em relação ao peso médio, limite inferior de especificação (LIE) e limite superior de especificação (LSE). Para a determinação desses limites, foram usadas as seguintes expressões:

$$
\begin{array}{ll}
\text { I. } & \text { LSC }=\mu+\mathrm{k} \sigma_{\mathrm{x}} ; \text { sendo } \mathrm{k}=3 \\
\text { II. } & \text { LIC }=\mu-\mathrm{k} \sigma_{\mathrm{x}} ; \text { sendo } \mathrm{k}=3
\end{array}
$$

O teste estatístico Shapiro Wilk foi utilizado para avaliar a normalidade da variável "peso". O nível de significância adotado foi de 5\%. Visto que os resultados do teste de normalidade frequentemente não são apresentados na literatura científica, optou-se pela não apresentação dos resultados do teste Shapiro Wilk. Os gráficos de controle foram gerados no software Microsoft ${ }^{\circledR}$ Excel®, com assinatura do Office 365 .

\section{RESULTADOS E DISCUSSÃO}

\subsection{Ensaios de identificação}

Os ensaios de identificação permitiram verificar a identidade do bicarbonato de sódio utilizado nos testes. Observou-se que todas as alíquotas testadas, após a adição da fenolftaleína, passaram de seu aspecto incolor para o de coloração rósea. Posteriormente, estas alíquotas ao serem aquecidas desprenderam gás e as colorações foram se tornando cada vez mais intensas, a qual a literatura denomina "vermelha".

A mudança de coloração observada foi possível em decorrência da presença da fenolftaleína. Ela é um indicador básico que se mantém incolor em soluções ácidas e adquire cor rosácea em solução básica [17]. No geral, esses indicadores são substâncias orgânicas fracamente básicas que mudam a coloração de acordo com a sua forma protonada ou desprotonada [18].

A mudança de intensidade na coloração observada foi em decorrência de um aumento gradativo do $\mathrm{pH}$, durante o aquecimento. No momento em que há uma dissolução do bicarbonato de sódio em água, forma-se ácido carbônico, que é fracamente ácido [19]. À medida que a solução é aquecida, o ácido carbônico libera o gás $\mathrm{CO}_{2}$, observado na formação de bolhas e água. Dessa forma, a solução diminui a sua acidez e deixa se sobrepor a basicidade do $\mathrm{OH}^{-}$, aumentando a intensidade da coloração.

O não cumprimento deste teste poderia sugerir falsificação ou erro de rotulagem do material, o que não foi observado em nenhuma das amostras analisadas. Portanto, as amostras analisadas dos três fabricantes cumprem o ensaio farmacopeico de identificação realizado.

\subsection{Ensaios de pureza}

Os testes de pureza são necessários para verificar as impurezas do fármaco e assegurar a sua qualidade. As análises realizadas fundamentaram-se na observação do aspecto da solução e da presença de carbonatos.

De acordo com a Farmacopeia Brasileira $5^{a}$ edição (2010) [16], a solução analisada deve estar límpida e incolor; não havendo uma estipulação de um valor mínimo de amostras para análise. 
Neste trabalho, realizou-se a análise em 5 amostras de cada laboratório, para uma avaliação com boa reprodutibilidade e confiabilidade dos testes. Dessa forma, todas as amostras analisadas apresentaram-se em conformidade.

A avaliação do valor $\mathrm{pH}$ também foi realizada para se avaliar a pureza em relação ao carbonato e nenhuma amostra se apresentou com um valor superior a $8,4\left(\mu_{\mathrm{A}}=7,68 ; \mu_{\mathrm{B}}=7,65 ; \mu_{\mathrm{C}}=7,62\right)$. Por esta razão, todas apresentaram-se conformes. Os resultados obtidos na determinação da pureza das amostras analisadas podem ser observados na Tabela 1.

Tabela 1. Determinação da pureza das amostras de bicarbonato de sódio em pó, com base no aspecto da solução (limpidez e coloração) e avaliação da pureza, levando em conta o carbonato ( $\mathrm{pH}$ ).

\begin{tabular}{cccc}
\hline & Laboratório A & Laboratório B & Laboratório C \\
\hline Leitura & $\mathbf{p H}$ & $\mathbf{p H}$ & $\mathbf{p H}$ \\
\hline $\mathbf{1}$ & 7,69 & 7,66 & 7,64 \\
$\mathbf{2}$ & 7,69 & 7,65 & 7,61 \\
$\mathbf{3}$ & 7,67 & 7,67 & 7,61 \\
$\mathbf{4}$ & 7,69 & 7,66 & 7,6 \\
$\mathbf{5}$ & 7,67 & 7,62 & 7,62 \\
\hline $\boldsymbol{\mu}_{\mathbf{x}}$ & 7,68 & 7,65 & 7,62 \\
\hline $\boldsymbol{\sigma}_{\mathbf{x}}$ & 0,01 & 0,02 & 0,01 \\
\hline DPR $(\boldsymbol{\%})$ & 0,14 & 0,25 & 0,20 \\
\hline Sendo $\mu_{\mathrm{x}}=$ média; $\sigma_{\mathbf{x}}=$ Desvio Padrão; DPR $(\%)=$ Desvio Padrão Relativo.
\end{tabular}

A avaliação do carbonato é importante, pois, assim como o dióxido de carbono e água, é um componente de decomposição do bicarbonato de sódio. Sabe-se que o $\mathrm{NaHCO}_{3}$ pode sofrer decomposição a uma temperatura de cerca de $100^{\circ} \mathrm{C}$ e por isso chega até a ser utilizado como fermento químico na preparação de pães e bolos, por exemplo [15, 20, 21]. É uma reação endotérmica e, por isso, ele pode ser utilizado como pó químico em extintores de incêndio [21].

\subsection{Determinação de peso}

Todas as amostras testadas encontravam-se como forma farmacêutica sólida acondicionadas em recipientes para doses múltiplas (pós). Nos testes para determinação de peso, as amostras analisadas dos três fabricantes cumprem o teste com uma média de resultados de $100 \%$ da massa encontrada em relação ao peso declarado, indicando homogeneidade no envase e o fornecimento do produto na quantidade informada.

Observa-se que os três fabricantes analisados cumprem o teste para determinação de peso, apresentando resultados acima do valor mínimo estabelecido pela Farmacopeia Brasileira (2010) [16] (Tabela 2).

De acordo com a Farmacopeia Brasileira (2010) [16], em apresentações com até 60g de peso, estas devem ter um percentual mínimo de $90 \%$ do peso declarado, enquanto nas apresentações entre $60-150 \mathrm{~g}$ de peso declarado o percentual mínimo em relação ao peso declarado deve ser de $90 \%$.

Analisando os valores obtidos, observou-se que houve pouca variação de peso entre as amostras e a média de todos os medicamentos averiguados. Ressalta-se que o desvio padrão relativo do bicarbonato de sódio do Laboratório $\mathrm{C}$ foi o menor em relação aos outros testados. Durante a execução do experimento, observou-se que o bicarbonato de sódio deste laboratório possuía um aspecto mais granulado em relação aos outros e era mais fácil de ser removido da embalagem para a pesagem. Provavelmente, esta característica repercutiu no seu melhor resultado. 
Tabela 2. Determinação de peso das amostras de bicarbonato de sódio em pó.

\begin{tabular}{|c|c|c|c|c|c|c|}
\hline \multirow{2}{*}{$\frac{\text { Amostra }}{\mathbf{N}^{\circ}}$} & \multicolumn{2}{|c|}{ Laboratório A } & \multicolumn{2}{|c|}{ Laboratório B } & \multicolumn{2}{|c|}{ Laboratório C } \\
\hline & Massa (g) & $(\%)$ & Massa (g) & $(\%)$ & Massa (g) & $(\%)$ \\
\hline 1 & 105,17 & 100,71 & 52,37 & 101,36 & 53,57 & 100,05 \\
\hline 2 & 104,88 & 100,44 & 51,22 & 99,13 & 53,41 & 99,75 \\
\hline 3 & 105,85 & 101,37 & 51,44 & 99,56 & 53,63 & 100,17 \\
\hline 4 & 103,09 & 98,72 & 51,40 & 99,48 & 53,23 & 99,41 \\
\hline 5 & 104,55 & 100,12 & 51,23 & 99,15 & 53,96 & 100,77 \\
\hline 6 & 103,51 & 99,12 & 52,14 & 100,91 & 53,09 & 99,16 \\
\hline 7 & 104,42 & 100,00 & 52,23 & 101,09 & 54,09 & 101,02 \\
\hline 8 & 103,92 & 99,52 & 51,88 & 100,40 & 53,54 & 100,00 \\
\hline 9 & 103,55 & 99,17 & 51,21 & 99,11 & 53,38 & 99,69 \\
\hline 10 & 105,29 & 100,83 & 51,57 & 99,80 & 53,53 & 99,98 \\
\hline Máximo & 105,85 & & 52,37 & & 54,09 & \\
\hline Mínimo & 103,09 & & 51,21 & & 53,09 & \\
\hline $\boldsymbol{\mu}_{\mathbf{x}}$ & 104,42 & 100 & 51,67 & 99,99 & 53,54 & 100 \\
\hline$\sigma_{x}$ & 0,90 & - & 0,45 & - & $\mathbf{0 , 3 0}$ & - \\
\hline DPR\% & 0,86 & - & $\mathbf{0 , 8 7}$ & - & $\mathbf{0 , 5 7}$ & - \\
\hline
\end{tabular}

Sendo $\mu_{\mathrm{x}}=$ média; $\sigma_{\mathrm{x}}=$ Desvio Padrão; DPR \% Desvio Padrão Relativo; \% = porcentagem em relação à média.

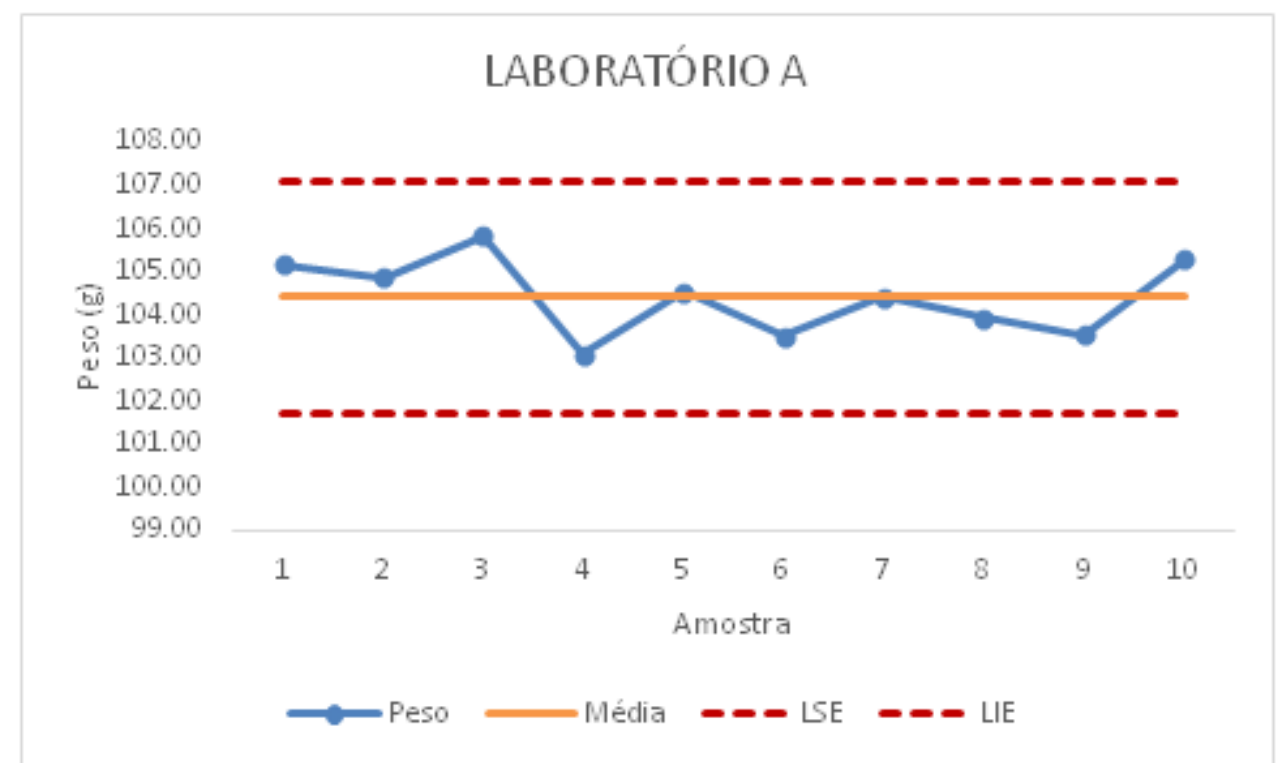

Figura 1. Carta controle das amostras de bicarbonato de sódio do laboratório A. Pa = Peso de cada amostra; $\mu_{x}=$ Média (104,42); LSE = Limite superior de especificação (107,11); LIE = Limite inferior de especificação $(101,74)$.

Determinou-se em relação à média, o peso máximo do LSE e o peso mínimo do LIE de cada formulação, descritos nas cartas de controles de cada laboratório (Figuras 1 a 3), onde se pode observar melhor os resultados analisados. 


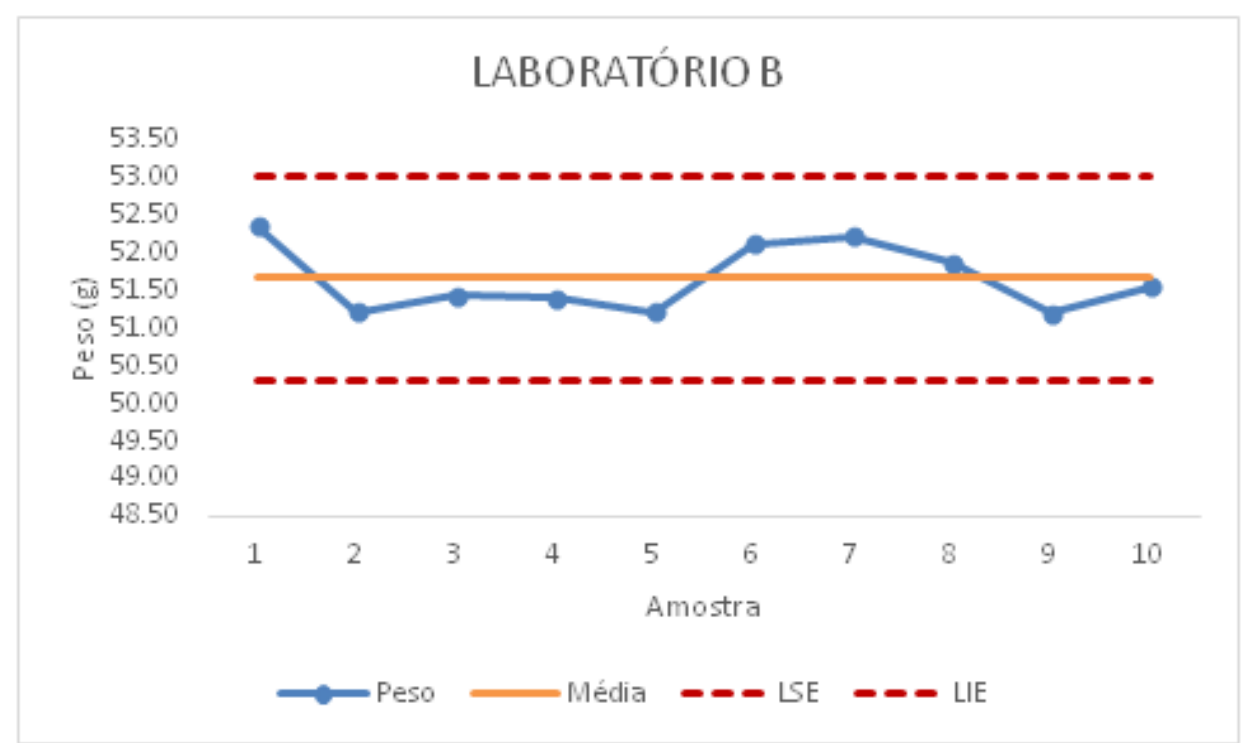

Figura 2. Carta controle das amostras de bicarbonato de sódio do laboratório B. Pa = Peso de cada amostra; $\mu_{x}=$ Média (51,67); LSE = Limite superior de especificação (53,02); LIE = Limite inferior de especificação $(50,32)$.

A estabilidade do bicarbonato de sódio pode envolver aspectos complexos de reações químicas, não podendo ser generalizada a um padrão. No entanto, sabe-se que a temperatura e a umidade relativa (UR) são fatores cruciais na sua manutenção, podendo resultar em um aumento ou diminuição do peso do bicarbonato de sódio e indicar alteração da qualidade do produto [22].

Ainda que a decomposição do bicarbonato de sódio aconteça a cerca de $100^{\circ} \mathrm{C}$, já se observou que em temperaturas bem menores este produto já pode sofrer decomposição. Quando se relaciona a temperatura e a umidade, em um ambiente com uma maior UR há a formação de um meio aquoso em que o dióxido de carbono, decorrente da decomposição, fica dissolvido. À medida em que a temperatura se eleva, há uma diminuição da solubilidade do meio e o dióxido de carbono é liberado na forma de gás [22].

Em detrimento dessas informações, já se observou que a $25^{\circ} \mathrm{C}$ e $93 \%$ de UR, há um aumento do peso do bicarbonato de sódio. Em contrapartida, a $40^{\circ} \mathrm{C}$ e $89 \%$ de UR ou $55^{\circ} \mathrm{C}$ e $82 \%$ de UR há uma diminuição do peso do bicarbonato de sódio, em decorrência da taxa de decomposição ser maior que a sorção da umidade, resultando na liberação de dióxido de carbono. Resultados de titulações ácidas mostraram que o bicarbonato de sódio em pó é estável abaixo de $76 \%$ de UR a $25^{\circ} \mathrm{C}$ e abaixo de $48 \%$ de $\mathrm{RH}$ a $40 \%$, respectivamente [22]. 


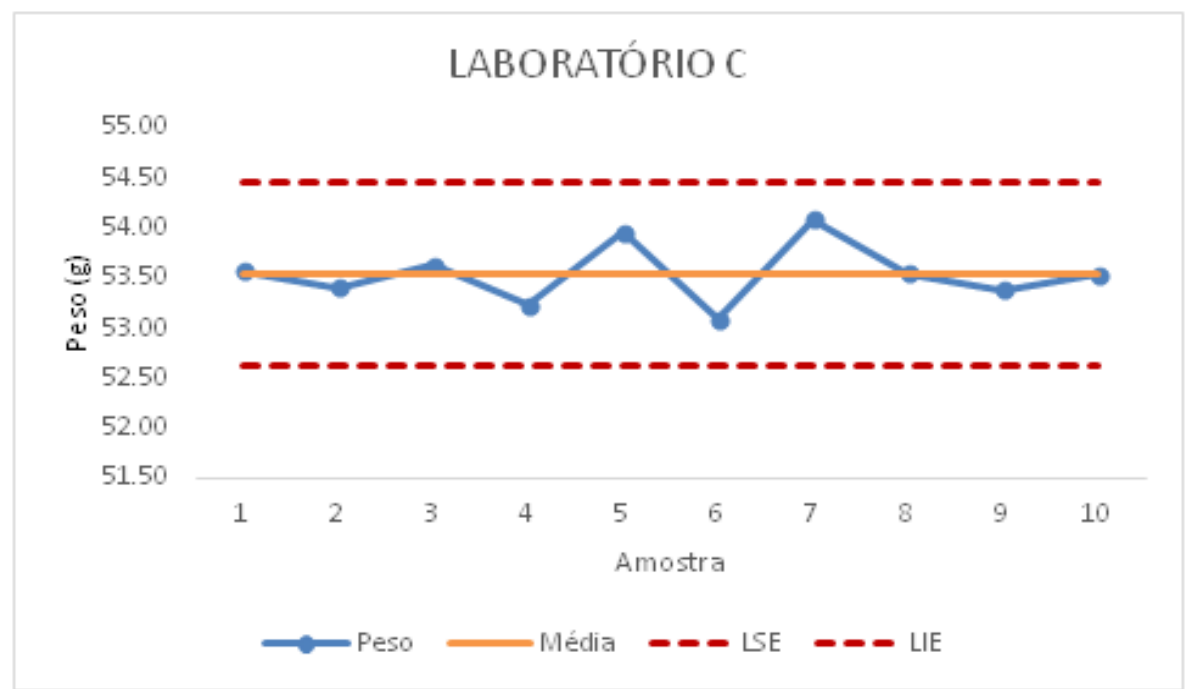

Figura 2. Carta controle das amostras de bicarbonato de sódio do laboratório $C$. Pa = Peso de cada amostra; $\mu_{x}=$ Média (53,54); LSE = Limite superior de especificação $(54,45) ;$ LIE = Limite inferior de especificação $(52,63)$.

As figuras 1-3 permitem avaliar o perfil de peso das amostras individualmente, podendo se observar melhor a homogeneidade dos valores obtidos. Dessa forma, percebe-se que nenhuma das amostras analisadas se encontrava com um valor superior ao LSE ou inferior ao LIE, confirmando a homogeneidade do peso dessas amostras e pouca interferência da temperatura e umidade.

Essa avaliação se torna importante em decorrência de São Luís (MA) ser uma região litorânea, próxima à linha do equador. O que resultaria numa exposição maior de temperatura e umidade ao bicarbonato de sódio. No entanto, observou-se que qualidade do bicarbonato de sódio se manteve, provavelmente em decorrência da presença de um farmacêutico em todos os locais de aquisição deste produto, respeitando as boas práticas para armazenagem de medicamentos, onde se é realizado diariamente o monitoramento de temperatura e umidade do local em que são armazenados. Os dados da Tabela 2 e as Figuras 1-3 permitem inferir que as amostras estão de acordo com a Farmacopeia Brasileira (2010) [16] e apresentam homogeneidade.

\subsection{Doseamento}

A administração de doses corretas está relacionada com a quantidade do componente ativo próximo da quantidade declarada. O teor, a média e o Desvio Padrão Relativo do doseamento das amostras de bicarbonato de sódio são apresentados na Tabela 3.

Tabela 3. Doseamento do bicarbonato de sódio em pó.

\begin{tabular}{cccc}
\hline Laboratório & $\mathbf{A}$ & $\mathbf{B}$ & $\mathbf{C}$ \\
\hline Leitura & Teor $(\boldsymbol{\%})$ & Teor $(\boldsymbol{\%})$ & Teor $(\boldsymbol{\%})$ \\
\hline $\mathbf{1}$ & 99,07 & 100,71 & 100,16 \\
$\mathbf{2}$ & 99,62 & 100,16 & 100,16 \\
$\mathbf{3}$ & 100,16 & 99,62 & 100,16 \\
$\mathbf{4}$ & 100,16 & 100,16 & 99,62 \\
$\mathbf{5}$ & 99,62 & 100,16 & 99,62 \\
\hline $\boldsymbol{\mu}_{\mathbf{x}}$ & 99,73 & 100,16 & 99,94 \\
\hline $\boldsymbol{\sigma}_{\mathbf{x}}$ & 0,46 & 0,38 & 0,30 \\
\hline DPR(\%) & 0,46 & 0,38 & 0,30 \\
\hline
\end{tabular}

Resultado CONFORME CONFORME CONFORME

Sendo $\mu_{\mathrm{x}}=$ média; $\sigma_{\mathrm{x}}=$ Desvio Padrão; DPR \% Desvio Padrão Relativo; \% = porcentagem em relação à média. 
Assim como na determinação da pureza, a Farmacopeia brasileira $5^{\text {a }}$ edição (2010) não estipula um valor mínimo de amostras para análise, a fim de se realizar uma análise com boa reprodutibilidade e confiabilidade dos testes, realizou-se a análise em 5 amostras de cada laboratório, conforme observado na Tabela 3. Os dados permitem avaliar que nenhuma amostra apresentou valores inferiores ao mínimo (99\%) ou superior ao máximo (101\%) da quantidade declarada, estabelecido na Farmacopeia Brasileira $5^{\mathrm{a}}$ ed [16]. Os valores de DPR (\%) evidenciam pouca variação entre as unidades e a média, o que sugere a homogeneidade entre as amostras analisadas no ensaio. Portanto, constata-se que todas as amostras estão em conformidade quanto ao teor de bicarbonato de sódio.

Durante a execução da pesquisa, não foram encontrados artigos avaliando a qualidade físicoquímica do bicarbonato de sódio. O cálculo de uniformidade de doses unitárias não foi necessário, pois as amostras estavam embaladas em recipientes de doses múltiplas.

A importância das análises de controle de qualidade torna-se cada vez mais evidente na manutenção da segurança e eficácia dos medicamentos. A diversidade de métodos e equipamentos simples e rápidos, viabilizam a execução de muitos ensaios. Assim como em outros medicamentos, o bicarbonato de sódio não está excluído de interferentes em sua qualidade, e por ser de fácil acesso e larga utilização, é de extrema importância que se avaliem os seus parâmetros de qualidade.

\section{CONCLUSÃO}

As amostras de bicarbonato de sódio, na forma farmacêutica de pó, adquiridas em farmácias no município de São Luís - MA, apresentaram resultados satisfatórios, cumprindo os testes selecionados. Os ensaios aplicados no estudo foram: identificação, pureza (carbonatos e aspecto da solução), determinação de peso e doseamento. Não houve variação de peso significativa entre as amostras, conforme verificado nas cartas de controle. No doseamento, a média dos resultados nos laboratórios: A $(99,73 \%)$, B (100,16\%) e C (99,94\%) manteve-se de acordo com o limite da especificação (99-101\%). Não foi realizado o teste de uniformidade de doses unitárias por se tratar de medicamento acondicionado em recipientes para doses múltiplas.

Os resultados obtidos na pesquisa do medicamento bicarbonato de sódio (pó) estavam em conformidade com as especificações da Farmacopeia Brasileira $5^{\mathrm{a}}$ edição, referente ao controle físico-químico, cumprindo assim os requisitos de qualidade físico-químico analisados na pesquisa.

\section{REFERÊNCIAS BIBLIOGRÁFICAS}

1. Gomes MA. Boas Práticas de Fabricação de Cosméticos, Produtos de Higiene e Saneantes; 2013. 105p. Available from: http://www.saude.pr.gov.br/arquivos/File/DiogoPracz/VigilanciaSanitaria/capacitacoes/controlequalid ade.pdf

2. Oliveira CLCG. Desenvolvimento de métodos analíticos e estudo de estabilidade [Doutorado em Farmácia]. Araraquara (SP): Universidade Estadual Paulista; 2009. 223p. Available from: https://repositorio.unesp.br/bitstream/handle/11449/100090/oliveiraclcgdrarafcf.pdf?sequence = lisAllowed $=\mathrm{y}$.

3. Corrêa JC. Qualidade dos medicamentos comercializados no Brasil segundo dados do Instituto Nacional de Controle de Qualidade em Saúde e do Instituto Adolf Lutz [Mestrado em Farmácia]. São Paulo (SP): Universidade de São Paulo; 2003. 152p. Available from: http://www.teses.usp.br/teses/disponiveis/9/9139/tde-30092011-122030/pt-br.php.

4. Agência Nacional de Vigilância Sanitária (Brasil). Resolução nº 67, de 8 de outubro de 2007. Dispõe sobre Boas Práticas de Manipulação de Preparações Magistrais e Oficinais para Uso Humano em farmácias. Diário Oficial da União 9 out 2007; Seção 1.

5. de Oliveira EA, Labra EM, Bermudez J. A produção pública de medicamentos no Brasil: uma visão geral. Cad Saúde Pública. 2006 nov; 22(11):2379-89. Available from: http://www.scielo.br/pdf/csp/v22n11/12.pdf.

6. Gennaro AR. Remington Farmacia. Panamericana. EM:Buenos Aires; 2003.v.2. 1388p. 
7. Brasil Agência Nacional de Vigilância Sanitária (ANVISA). O que devemos saber sobre medicamentos. Santa Catarina; 2010. 100p. Cartilha. Available from: http://www.vigilanciasanitaria.sc.gov.br/index.php/download/category/112medicamentos?download=102: cartilha-o-que-devemos-saber-sobre-medicamentos-anvisa.

8. Agência Nacional de Vigilância Sanitária (Brasil). Instrução Normativa $n^{\circ} .11$, de 29 de setembro de 2016. Dispõe sobre a lista de medicamentos isentos de prescrição. Diário Oficial da União 11 set 2016; Seção 1.

9. Shelton J, kumar GVP. Sodium Bicarbonate-A Potent Ergogenic Aid? SCIRP. 2010;1(1):1-4. Available from: http://dx.doi.org/10.4236/fns.2010.11001.

10. Hypofarma. Benefícios do bicarbonato de sódio; 2016. Bulário da Anvisa. Available from: http://www.anvisa.gov.br/datavisa/filabula/frmVisualizarBula.asp?pNuTransacao 15953722016 pIdAnexo $=3351441$.

11.SBQ. Bicarbonato de sódio, Available from: http://qnint.sbq.org.br/qni/popupvisualizarMolecula.php?id = yBhhf idwkzol432KJ2U0avoqrv7cF c1dAqGY oP7DviPMs0IDpUFW EDw7H4L8AXAV 3UC - 98SM dqW BN aS38G1RA.

12. P Junior DM. A seleção de medicamentos para o monitoramento da qualidade laboratorial no Brasil: articulação entre a vigilância sanitária e a política nacional de medicamentos, [Mestrado]. Rio de Janeiro (RJ): Escola Nacional de Saúde Pública Sergio Aruouca; 2007. 142p. Available from: http://www6.ensp.fiocruz.br/visa/files/DissertacaoDurval.pdf.

13. Felli VMA. Fármacos para tratar doenças gastroesofágicas; 2018. 45p. Slide. Available from: https://social.stoa.usp.br/articles/0016/5529/Gastrite-profV eni.pdf.

14. Golan DE et al. Princípios de Farmacologia: a base fisiopatológica da farmacoterapia. 3. Ed. Rio de Janeiro: Guanabara Koogan, 2014.

15. Labsynth. Ficha de informações de segurança de produtos químicos: Bicarbonato de Sódio; 2017. 4p. Available from: http://downloads.labsynth.com.br/FISPQ/rv2012/FISPQ\%20Bicarbonato\%20de\%20Sodio.pdf.

16. Brasil Farmacopeia Brasileira, v 1. 5ed. Brasília: ANVISA; 2010. 546p.

17. Antunes M, Pacheco MA, Giovanela M. Proposta de uma atividade experimental para a determinação do pH no Ensino Médio. In XIV Encontro Nacional de Ensino de Química (XIV ENEQ); Curitiba; 2008.8p.

18. Terci, R. Indicadores naturais de pH: usar papel ou solução? Quím nova. 2001;(4):684-88.

19. Ayala JD. Química de ácidos e bases. Minas Gerais. [homepage na internet] 39p. Available from: http://qui.ufmg.br/ ayala/matdidatico/acidobase.pdf.

20. Lee JD. 1999. Química Inorgânica não tão concisa. Ed. E. Blücher: São Paulo.

21. Maia A de S, Osorio VKL. Decomposição térmica do bicarbonato de sódio: do processo Solvay ao diagrama tipo Ellingham. Quím Nova. 2003;26(4):595-601.

22. Kuu et al. Effect of relative humidity and temperature on moisture sorption and stability of sodium bicarbonate powder. Int J Pharmac. 1998;166:167-175. 